Check for updates

Cite this: RSC Adv., 2019, 9, 9342

\title{
Electronic structure of two-dimensional In and Bi metal on BN nanosheets
}

\author{
Maolin Bo, (D) a Jibiao Li, ${ }^{a}$ Chuang Yao, (D) a Zhongkai Huang, ${ }^{a}$ Lei Li, ${ }^{\text {*a }}$ \\ Chang $Q$. Sun (D) ab and Cheng Peng (D) *a
}

The electronic structures of two-dimensional (2D) indium (In) and bismuth (Bi) metal on BN nanosheets are systematically studied using hybrid density functional theory (DFT). We found that 2D In and Bi metal effectively modulate the band gap of a BN nanosheet. We also found that the indirect band gap of the $2 \mathrm{D} \mathrm{In}$ and $\mathrm{Bi}$ metal electronic structures are 0.70 and $0.09 \mathrm{eV}$, respectively. This modulation originates from the charge transfer between the 2D metal and BN nanosheet interfaces, as well as from the electron redistribution of the $\mathrm{In} / \mathrm{BN}$ and $\mathrm{Bi} / \mathrm{BN}$ heterojunctions of the $\mathrm{s}$ and $\mathrm{p}$ orbitals. Our results provide an insight into 2D In/BN and $\mathrm{Bi} / \mathrm{BN}$ heterojunctions, which should be useful in the design of $2 \mathrm{D} \ln$ and $\mathrm{Bi}$ metal-semiconductor-based devices.

Received 25th January 2019

Accepted 18th March 2019

DOI: $10.1039 / c 9 r a 00673 g$

rsc.li/rsc-advances

a $\mathrm{WTe}_{2}$ substrate. ${ }^{14}$ Simultaneously, when $2 \mathrm{D}$ materials are stacked together, they can develop surprising electronic and photocatalytic properties. ${ }^{15,16}$ For example, Wang et al. reported that a $\mathrm{SrTiO}_{3} / \mathrm{NaTaO}_{3}$ heterojunction exhibits improved $\mathrm{SrTiO}_{3}$ photocatalytic properties. ${ }^{17}$ Zhang et al. found that $\mathrm{MoS}_{2} / \mathrm{Ni}_{3} \mathrm{~S}_{2}$ heterostructures have highly electrochemical properties. ${ }^{18}$ Rivera et al. observed interlayer excitons in a $\mathrm{MoSe}_{2} / \mathrm{WSe}_{2}$ heterostructure when subjected to photoluminescence excitation spectroscopy. ${ }^{19}$ Therefore, twodimensional heterojunctions can change the electronic states, band gap, and photocatalytic properties, as well as the physical and chemical properties that can be used in the design of new devices..$^{20-22}$

In the present study, we determined the band gap of a single honeycomb BN sheet to be $4.76 \mathrm{eV}$. Density functional calculations showed that the band gap can be tuned using $\mathrm{Bi} / \mathrm{BN}$ and In/BN heterostructures, for which the band gaps are 0.70 and $0.16 \mathrm{eV}$, respectively. Therefore, we can change the band structure by adding $2 \mathrm{D}$ metal to a $2 \mathrm{D}$ semiconductor. The results of the present study provide a new route to the design of desirable semiconductors using 2D metal and semiconductor heterostructures.

\section{Methods}

The energetics and electronic properties of $\mathrm{Bi}, \mathrm{In}, \mathrm{BN}, \mathrm{Bi} / \mathrm{BN}$, and In/BN structures were analyzed from first principles. The DFT calculations used the projector-augmented wave potentials of the hybrid density functional, which was implemented in the CASTEP software. We used the HSE06 (ref. 23) hybrid density function to describe the electron exchange and correlation potential. The $2 \mathrm{D}$ stable structures of $\mathrm{Bi}, \mathrm{In}, \mathrm{BN}, \mathrm{Bi} / \mathrm{BN}$, and $\mathrm{In} /$ BN are shown in Fig. 1. For the DFT calculations, we used the 
a

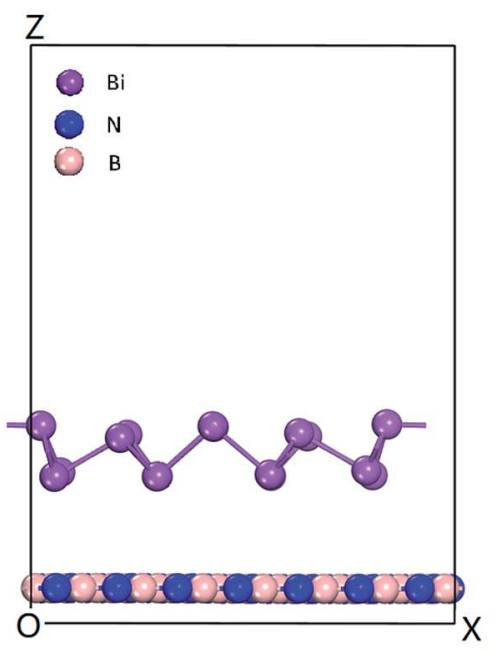

b

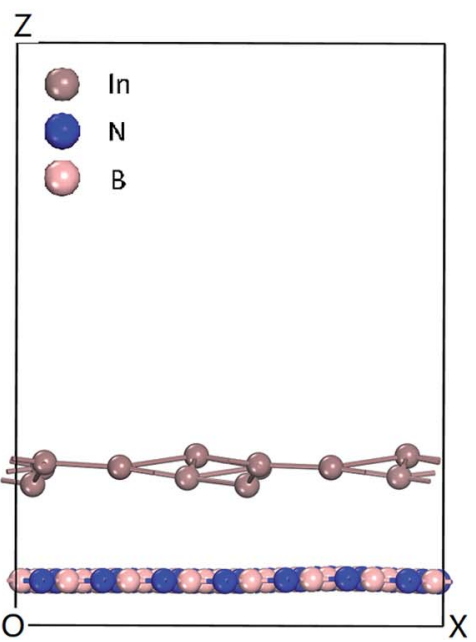

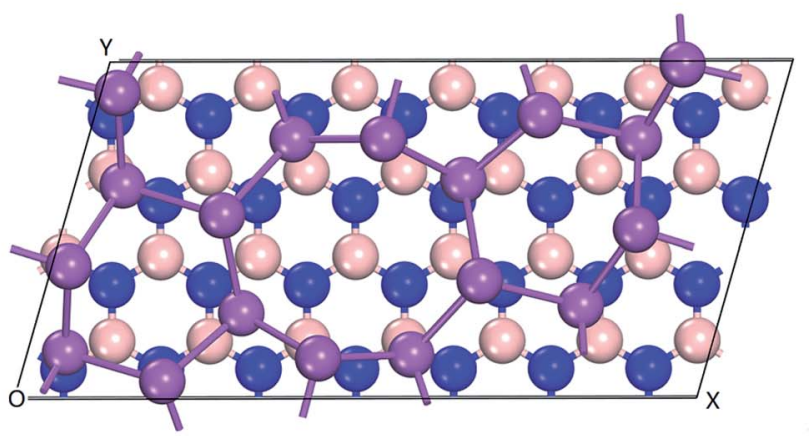

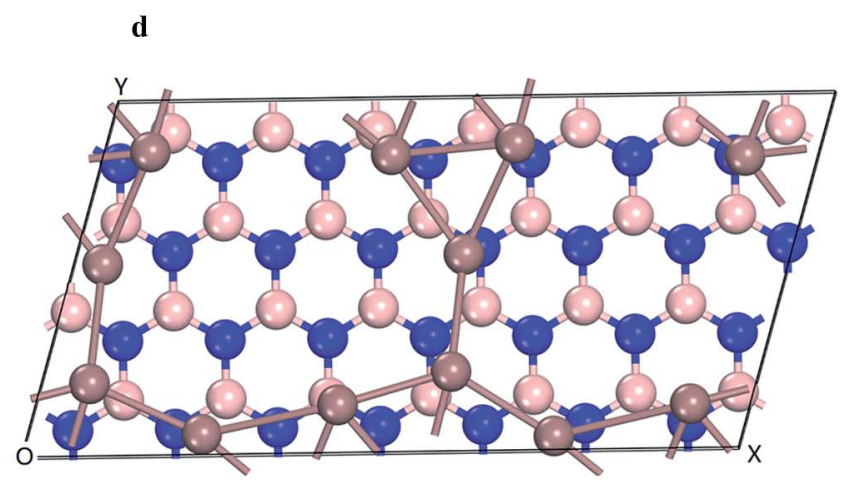

Fig. 1 Heterostructures of $\mathrm{Bi} / \mathrm{BN}$ and $\ln / \mathrm{BN}(\mathrm{a}$ and $\mathrm{b}$ ) side views and ( $\mathrm{c}$ and $\mathrm{d}$ ) top views.

Vienna ab initio simulation package (VASP) to optimize the initial structure such that the structure would converge faster. Then, we used the CASTEP software to optimize the structure

Table 1 Heterojunction formation energy

\begin{tabular}{llllllll}
\hline \multicolumn{2}{l}{$E_{\text {total }}^{\text {heterstructure }}(\mathrm{eV})$} & \multicolumn{2}{l}{$E_{\text {total }}^{\mathrm{In}(\mathrm{Bi})}(\mathrm{eV})$} & \multicolumn{2}{l}{$E_{\text {total }}^{\mathrm{BN}}(\mathrm{eV})$} & $E_{\text {form }}(\mathrm{eV})$ \\
\hline $\mathrm{In} / \mathrm{BN}$ & -10431.09 & In & -647.19 & $\mathrm{BN}$ & -9779.61 & -4.29 \\
$\mathrm{Bi} / \mathrm{BN}$ & -43 & 134.74 & $\mathrm{Bi}$ & -33349.13 & $\mathrm{BN}$ & -9779.60 & -6.01
\end{tabular}

and other properties. We assumed that the $\mathrm{Bi} / \mathrm{BN}$ and In/BN heterostructures of the atomic layer would influence the van der Waals force and relax the lattice constant and atomic position. The plane wave cut-off value was $700 \mathrm{eV}$. The $k$-points of the Brillouin zone were employed for sampling to relax the lattice constants of $2 \times 4 \times 1$. The vacuum space was approximately $16 \AA$. In the calculations, the criteria affecting the atom force convergence and energy were set to $10^{-6} \mathrm{eV}$ and $0.01 \mathrm{eV}$ $\AA^{-1}$, respectively.

Table 2 Correspondence between settings of atomic layer spacing and band gaps of $\mathrm{Bi} / \mathrm{BN}$ and $\ln / \mathrm{BN}$ heterojunctions ${ }^{a}$

\begin{tabular}{|c|c|c|c|c|c|c|c|c|}
\hline \multirow[b]{2}{*}{ Structures } & \multirow{2}{*}{$\begin{array}{l}\text { Layer spacing } \\
(\AA)\end{array}$} & \multirow{2}{*}{$\begin{array}{l}\text { Band gap } \\
\text { (eV) }\end{array}$} & \multicolumn{3}{|l|}{ Angles } & \multicolumn{3}{|c|}{ Lattice parameters } \\
\hline & & & $\alpha$ & $\beta$ & $\gamma$ & $a$ & $b$ & $c$ \\
\hline $\mathrm{Bi} / \mathrm{BN}$ & 4.45 & 0.70 & $88.54^{\circ}$ & $88.62^{\circ}$ & $73.99^{\circ}$ & $17.59 \AA$ & $9.04 \AA ̊ ̊$ & $23.05 \AA$ \\
\hline $\mathrm{In} / \mathrm{BN}$ & 3.77 & 0.16 & $89.91^{\circ}$ & $89.98^{\circ}$ & $73.97^{\circ}$ & $17.58 \AA$ & $9.06 \AA$ & $23.00 \AA$ \\
\hline
\end{tabular}

${ }^{a}$ Angles and lattice parameters of $\mathrm{Bi} / \mathrm{BN}$ and $\mathrm{In} / \mathrm{BN}$ heterojunctions. 


\section{Results and discussion}

We calculated the formation energy of the $\mathrm{Bi} / \mathrm{BN}$ and $\mathrm{In} / \mathrm{BN}$ heterostructures. The formation energy $E_{\text {form }}$ is defined as:

$$
E_{\mathrm{form}}=E_{\text {total }}^{\text {heterostructure }}-E_{\mathrm{total}}^{\mathrm{Bi}(\mathrm{In})}-E_{\mathrm{total}}^{\mathrm{BN}}(\mathrm{eV})
$$

These negative formation energies mean that the $2 \mathrm{D}$ heterostructures are energetically favorable. ${ }^{24}$ A lower $E_{\text {form }}$ value means that the calculated heterostructures have a lower energy state and a more stable configuration, suggesting that the structures could be synthesized in the laboratory. The formation energies $E_{\text {form }}$ are shown in Table 1.

The electronic structures and band gaps of $\mathrm{Bi}, \mathrm{In}, \mathrm{BN}, \mathrm{Bi} / \mathrm{BN}$, and $\mathrm{In} / \mathrm{BN}$ were calculated. For the $\mathrm{Bi} / \mathrm{BN}$ and $\mathrm{In} / \mathrm{BN}$ heterostructures, we considered the influence of the van der Waals forces, assuming the changes in the internal plane structure to be small and negligible. As can be seen from Fig. 1, the twodimensional structure requires some spacing to maintain its stability. We set the initial vertical distance between the bottom $\mathrm{BN}$ layer and the top metallic layer to 3.0 ̊. The atomic layer distances between the two monolayers in the heterostructures, after relaxation, are listed in Table 2 . The layer distances of the $\mathrm{Bi} / \mathrm{BN}$ and $\mathrm{In} / \mathrm{BN}$ heterostructures are 4.45 and $3.77 \AA$, respectively.

In the $\mathrm{Bi} / \mathrm{BN}$ and $\mathrm{In} / \mathrm{BN}$ heterostructures, the average bond lengths of the In-In and $\mathrm{Bi}-\mathrm{Bi}$ metal bonds are 3.107 and 3.067 $\AA$, respectively. The In-In and $\mathrm{Bi}-\mathrm{Bi}$ metal bulk bond lengths are 4.36 and 3.379 $\AA$, respectively. The In-In and $\mathrm{Bi}-\mathrm{Bi}$ bond lengths in the $\mathrm{Bi} / \mathrm{BN}$ and $\mathrm{In} / \mathrm{BN}$ heterostructures were found to be slightly shorter than the In and Bi metal bulk bond lengths, which can be attributed to the reconstruction of the surface atoms to accommodate the surface bond contraction caused by the lattice strain. As shown in Fig. 1, the metals have a plane geometric structure. Meanwhile, the $\mathrm{Bi}$ metal has a curved honeycomb geometric structure. The In-In metal and $\mathrm{Bi}-\mathrm{Bi}$ metal bond angles in the $\mathrm{Bi} / \mathrm{BN}$ and $\mathrm{In} / \mathrm{BN}$ heterostructures are $78.54-99.19^{\circ}$ and $106.16-166.82^{\circ}$, respectively. This curved honeycomb structure of the Bi metal helps to stabilize the layered structure, in the same way as blue phosphorene, germanene, silicene, and stanene.

Energy distribution is also important to physical and chemical systems. The energy distribution determines the state of the system and the electronic properties of the material. The band gap, valence band, and conduction band can be clearly obtained from the DOS diagram. The local densities of states (LDOS) for the 2D structures of $\mathrm{Bi}, \mathrm{In}, \mathrm{BN}, \mathrm{Bi} / \mathrm{BN}$, and $\mathrm{In} / \mathrm{BN}$ are shown in Fig. 2. For the Bi and In metals, the conduction-band bottom and valence-band top mainly consists of Bi $6 \mathrm{p}^{3}$ (In $5 \mathrm{p}^{1}$ ) states coupled with small amounts of Bi $6 s^{2}\left(\right.$ In $\left.5 s^{2}\right)$ states. The semiconductor characteristics of the monolayer Bi and In metal are mainly due to the atomic $\mathrm{p}$ and s orbitals at the Fermi level.

We compared the LDOS values of the Bi 6 s orbit, Bi $6 \mathrm{p}$ orbit, and BN, as shown in Fig. 2(a). Fig. 2(b) shows the LDOS values of the $\mathrm{Bi} / \mathrm{BN}$ heterostructures. Differences can be seen in the DOS values of the $\mathrm{BN}$ sheet and $\mathrm{Bi} / \mathrm{BN}$ heterostructures at the Fermi
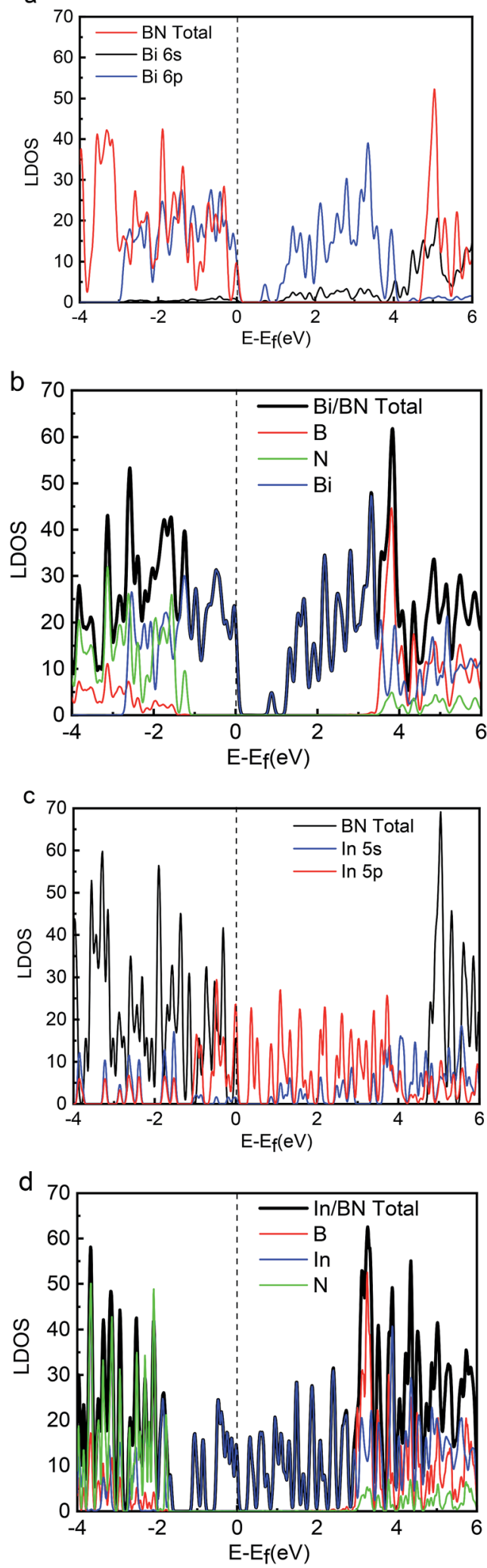

Fig. 2 LDOS values for $\mathrm{Bi}, \ln , \mathrm{BN}, \mathrm{Bi} / \mathrm{BN}$, and $\ln / \mathrm{BN}$ structures.

level. The electronic contribution of the BN sheet to the DOS can be attributed to the $\mathrm{B}$ and $\mathrm{N}$ atoms at the Fermi level. However, the electronic contribution of the DOS of the $\mathrm{Bi} / \mathrm{BN}$ 
heterostructures at the Fermi level is mainly caused by the $\mathrm{Bi}$ metal. Similar DOS values were also observed for the $\mathrm{BN}$ and $\mathrm{Bi}$ / BN heterostructures, as shown in Fig. 2(c) and (d). The s and p electrons of In and Bi metal fill the top of the valence band of the BN sheets. Fig. 3 shows that the electronic contribution and charge transfer of the valence band maximum (VBM) and conduction band minimum (CBM) of the Bi/BN and In/BN heterostructures at the Fermi level are mainly caused by the $\mathrm{Bi}$ and In metal. These results are in good agreement with the latest model of electron transfer at a Ag/graphite heterojunction. ${ }^{25}$

Our computations show that monolayer $\mathrm{Bi}$ and In metal feature a semiconductor band gap. To gain further insights, the VBM and the CBM of Bi and In are mainly composed of the $\mathrm{p}$ and s orbitals of electrons. We found that the main peak of the DOS in the CBM lies at $0.70 \mathrm{eV}$ for $\mathrm{Bi}, 0.09 \mathrm{eV}$ for In, $4.76 \mathrm{eV}$ for $\mathrm{BN}, 0.16 \mathrm{eV}$ for $\mathrm{Bi} / \mathrm{BN}$, and $0.70 \mathrm{eV}$ for In/BN. Most importantly, we observed that the band gap of the metal $\mathrm{Bi}$ is $0.70 \mathrm{eV}$. These results demonstrate that a new band gap has been formed in the metallic Bi. Therefore, the two-dimensional structure of the Bi metal has been converted into a semiconductor material. Similar electronic structure transitions from a metal to a semiconductor are also observed for the monolayer of metallic In.

Geometric structure determines the electronic properties. The Fig. 4(b), Bi/BN band gap is $0.7 \mathrm{eV}$ which is same to the band gap of $\mathrm{Bi}(0.7 \mathrm{eV})$ in Fig. 4(a). The geometric structure of $\mathrm{Bi}$ metal is comparable to the geometric structure of $\mathrm{Bi}$ on $\mathrm{BN}$ sheet; we found that its atomic position does not change much. The In/BN band gap is $0.16 \mathrm{eV}$ which is larger than the band gap of In $(0.09 \mathrm{eV})$ in Fig. $4(\mathrm{c})$. We found some changes in the atomic positions, as shown in the Table 3. Fig. 4 shows not only the band gaps of the $\mathrm{Bi} / \mathrm{BN}$ and $\mathrm{In} / \mathrm{BN}$ heterostructures, but also those of the monolayers of $\mathrm{Bi}$, In, and $\mathrm{BN}$. The band gaps of the $\mathrm{Bi} / \mathrm{BN}$ and In/BN heterostructures, as calculated by hybrid DFT, are 0.70 and $0.16 \mathrm{eV}$, respectively, which are 4.06 and $4.60 \mathrm{eV}$ lower than the corresponding values for the monolayer $\mathrm{BN}$ sheet. Previous experimental and theoretical studies of the band gaps of Bi on a SiC substrate yielded a value of $0.67 \mathrm{eV}$ (ref. 10) while for a single honeycomb $\mathrm{BN}$ sheet, the value was $4.80 \mathrm{eV}{ }^{26}$ We studied the $\mathrm{Bi} / \mathrm{BN}$ and $\mathrm{In} / \mathrm{BN}$ heterostructures, finding that the band gap is smaller than that of the $\mathrm{BN}$ sheet, implying that the band structure can be adjusted by using $2 \mathrm{D}$ metal with semiconductor properties.
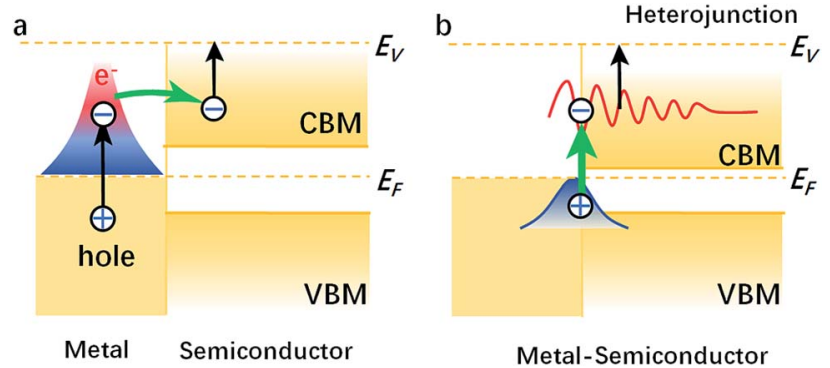

Fig. 3 VBM and CBM of (a) metal, semiconductor and metal (b) metalsemiconductor heterostructures.
Layered $\mathrm{Bi} / \mathrm{BN}$ and $\mathrm{Bi} / \mathrm{BN}$ heterojunctions configured using $\mathrm{Bi}$ and In metal were synthesized in the laboratory using molecular beam epitaxy. We could control the band structure by
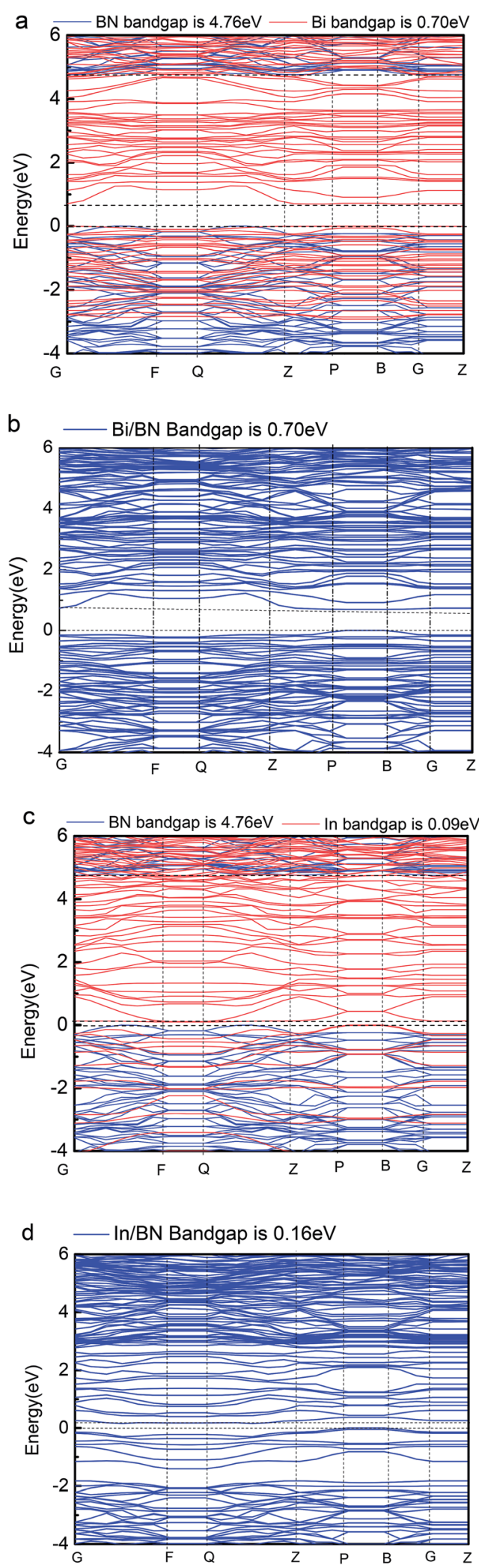

Fig. 4 Band gaps of $\mathrm{Bi}, \ln , \mathrm{BN}, \mathrm{Bi} / \mathrm{BN}$, and $\ln / \mathrm{BN}$ structures. 
Table 3 Atomic positions of $\mathrm{Bi}$ and In metal

\begin{tabular}{|c|c|c|c|c|c|c|}
\hline & $X$ & Y & $Z$ & $X$ & $Y$ & $Z$ \\
\hline & $\mathrm{Bi} / \mathrm{BN}$ & & & $\mathrm{Bi}$ & & \\
\hline $\mathrm{Bi}$ & 2.71849 & 8.04324 & 7.88434 & 2.69243 & 8.02398 & 7.82213 \\
\hline $\mathrm{Bi}$ & 3.85548 & 0.60316 & 7.37952 & 3.86017 & 0.63672 & 7.40532 \\
\hline $\mathrm{Bi}$ & 9.55824 & 6.84850 & 7.83619 & 9.55131 & 6.89164 & 7.74978 \\
\hline $\mathrm{Bi}$ & 11.60958 & 5.72985 & 5.88509 & 11.63010 & 5.71193 & 5.91919 \\
\hline $\mathrm{Bi}$ & 16.13413 & 6.79861 & 5.91527 & 16.07899 & 6.78490 & 5.96873 \\
\hline $\mathrm{Bi}$ & 2.83437 & 5.61181 & 6.01296 & 2.88017 & 5.57781 & 6.04338 \\
\hline $\mathrm{Bi}$ & 1.34126 & 1.30908 & 5.82265 & 1.38841 & 1.30555 & 5.87702 \\
\hline $\mathrm{Bi}$ & 5.88252 & 2.31468 & 5.84223 & 5.84379 & 2.34036 & 5.89016 \\
\hline $\mathrm{Bi}$ & 7.87431 & 1.19976 & 7.85439 & 7.87135 & 1.16233 & 7.76660 \\
\hline $\mathrm{Bi}$ & 13.60277 & 7.44120 & 7.46776 & 13.57875 & 7.42737 & 7.46684 \\
\hline $\mathrm{Bi}$ & 17.28458 & 8.75694 & 7.95300 & 17.31905 & 8.73475 & 7.90554 \\
\hline $\mathrm{Bi}$ & 14.63224 & 2.50331 & 6.09407 & 14.61604 & 2.50333 & 6.14430 \\
\hline $\mathrm{Bi}$ & 5.40258 & 4.87267 & 7.51546 & 5.42228 & 4.89841 & 7.50947 \\
\hline $\mathrm{Bi}$ & 7.21669 & 6.78895 & 5.86159 & 7.16932 & 6.84462 & 5.89615 \\
\hline $\mathrm{Bi}$ & 10.25366 & 1.24239 & 5.92633 & 10.29354 & 1.22881 & 5.96412 \\
\hline $\mathrm{Bi}$ & 12.04020 & 3.18445 & 7.58550 & 12.04791 & 3.18310 & 7.57306 \\
\hline $\mathrm{Bi}$ & 16.07444 & 4.50836 & 7.93710 & 16.09822 & 4.49188 & 7.90992 \\
\hline \multirow[t]{2}{*}{$\mathrm{Bi}$} & 1.44893 & 3.58079 & 7.86522 & 1.42300 & 3.59027 & 7.82697 \\
\hline & In/BN & & & In & & \\
\hline In & 4.41351 & 0.54878 & 6.24623 & 4.73354 & 0.69648 & 6.17675 \\
\hline In & 13.04933 & 0.38548 & 6.25520 & 13.50201 & 0.68650 & 6.19401 \\
\hline In & 2.04916 & 4.74593 & 5.54666 & 1.78949 & 4.79518 & 6.14179 \\
\hline In & 10.90435 & 4.87502 & 5.53906 & 10.65058 & 4.86892 & 6.14754 \\
\hline In & 9.16040 & 7.34008 & 5.82363 & 9.03537 & 7.23983 & 6.17652 \\
\hline In & 17.82898 & 7.19784 & 5.88436 & 17.74978 & 7.17751 & 6.18043 \\
\hline In & 7.75626 & 1.22207 & 6.70586 & 7.73500 & 1.14958 & 6.16801 \\
\hline In & 16.40263 & 1.13095 & 6.72311 & 16.48652 & 1.07629 & 6.17721 \\
\hline In & 3.25284 & 7.49042 & 6.21517 & 3.02228 & 7.48151 & 6.14018 \\
\hline In & 12.19995 & 7.58643 & 6.26118 & 11.87791 & 7.56562 & 6.15030 \\
\hline In & 1.68308 & 1.82715 & 6.42129 & 1.91794 & 1.77129 & 6.15881 \\
\hline In & 10.54597 & 2.00315 & 6.35550 & 10.74625 & 1.84477 & 6.16617 \\
\hline
\end{tabular}

changing the local atomic orbital interactions. Given the special electronic properties, the deformation charge density can be used to determine the characteristics of the atomic bond through the corresponding energy density distribution. Negative charge density regions cause electrons to diverge and positrons to accumulate, forming charge-density regions. The transfer of the charge is represented by a deformation charge density map using different colors. The charge accumulated between two atoms forms a covalent bond; however, charge transfer or divergence gives rise to an ionic bond. For example, the point at which the covalent bond electrons converge is between two atoms, such that an ionic bond converges to one side.

Fig. 5 shows the deformation charge density. We believe that the formation of the $\mathrm{Bi} / \mathrm{BN}$ and $\mathrm{Bi} / \mathrm{BN}$ heterostructures is mainly due to the transfer of the charge and electronic density distribution. The scale indicates the charge distribution. The increase and decrease in the number of electrons is shown in blue and red, respectively. For the Bi/BN and In/BN heterostructures, the BN nanosheet deformation charge density is shown in red and blue. That is to say, a positive deformation charge density causes the electron density to increase. In contrast, the deformation charge density of the $2 \mathrm{D}$ In and $\mathrm{Bi}$ metals is mainly shown in red. The deformation charge density

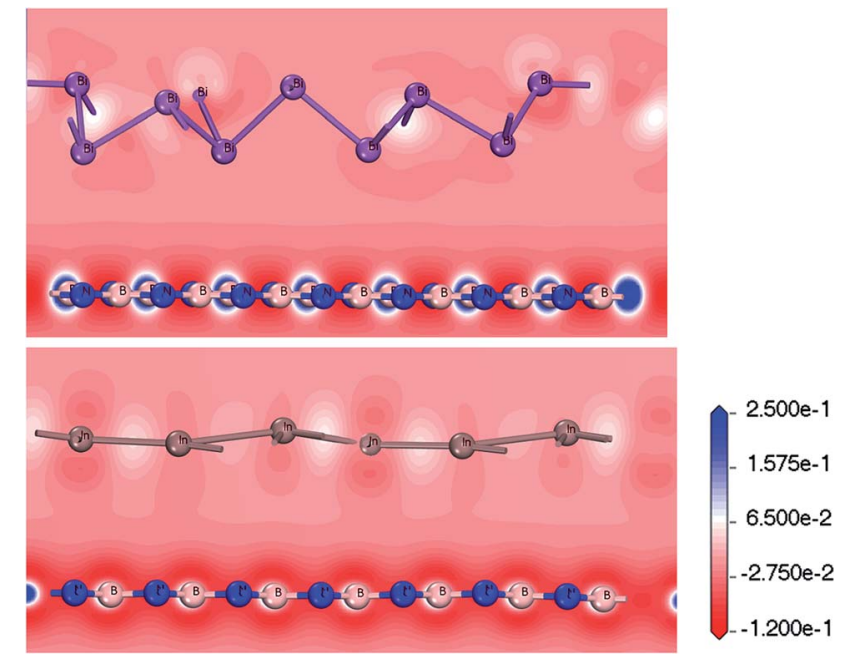

Fig. 5 Charge density difference between $\mathrm{Bi} / \mathrm{BN}$ and $\ln / \mathrm{BN}$ heterostructures.

is negative, indicating that electrons are lost from these parts. We examined the $\mathrm{Bi} / \mathrm{BN}$ and $\mathrm{Bi} / \mathrm{BN}$ heterostructures and found that they all have indirect band gaps and interlayer coupling.

\section{Conclusion}

We studied the electronic properties and atomic bonding of $\mathrm{Bi} /$ $\mathrm{BN}$ and In/BN heterojunctions containing 2D In and Bi metals, and compared the results with the corresponding monolayer 2D metals and BN nanosheets. The band gap of In/BN and In are $0.16 \mathrm{eV}$ and $0.09 \mathrm{eV}$, respectively. The $\mathrm{Bi} / \mathrm{BN}$ band gap is $0.7 \mathrm{eV}$ which is same to the band gap of Bi. The calculated band gaps for $\mathrm{Bi}, \mathrm{In}, \mathrm{BN}, \mathrm{Bi} / \mathrm{BN}$, and $\mathrm{In} / \mathrm{BN}$ indicate that these $2 \mathrm{D}$ metal and metal-semiconductor heterojunctions have suitable band gaps. Theoretical predictions indicate that $\mathrm{Bi}, \mathrm{In}, \mathrm{BN}, \mathrm{Bi} / \mathrm{BN}$, and In/BN are promising candidates for new 2D materials. These findings will be useful to the design of related optoelectronic devices.

\section{Conflicts of interest}

The authors declared that they have no conflicts of interest to this work.

\section{Acknowledgements}

This work was supported by Chongqing Municipal Education Commission (Grant No. KJ1712310).

\section{References}

1 S. Manzeli, D. Ovchinnikov, D. Pasquier, O. V. Yazyev and A. Kis, Nat. Rev. Mater., 2017, 2, 17033.

2 S. Z. Butler, S. M. Hollen, L. Cao, Y. Cui, J. A. Gupta, H. R. Gutiérrez, T. F. Heinz, S. S. Hong, J. Huang, A. F. Ismach, E. Johnston-Halperin, M. Kuno, V. V. Plashnitsa, R. D. Robinson, R. S. Ruoff, 
S. Salahuddin, J. Shan, L. Shi, M. G. Spencer, M. Terrones, W. Windl and J. E. Goldberger, ACS Nano, 2013, 7, 28982926.

3 A. S. Rodin, A. Carvalho and A. H. Castro Neto, Phys. Rev. Lett., 2014, 112, 176801.

4 M. Xu, T. Liang, M. Shi and H. Chen, Chem. Rev., 2013, 113, 3766-3798.

5 J. Zhao, Q. Deng, A. Bachmatiuk, G. Sandeep, A. Popov, J. Eckert and M. H. Rümmeli, Science, 2014, 343, 1228.

6 C. Q. Sun, Relaxation of the Chemical Bond, Springer Singapore, 2014.

7 M. Jankowski, D. Kaminski, K. Vergeer, M. Mirolo, F. Carla, G. Rijnders and T. R. Bollmann, Nanotechnology, 2017, 28, 155602.

8 M. Pumera and Z. Sofer, Adv. Mater., 2017, 29, 1605299.

9 S. Zhang, Z. Yan, Y. Li, Z. Chen and H. Zeng, Angew. Chem., 2015, 54, 3112-3115.

10 F. Reis, G. Li, L. Dudy, M. Bauernfeind, S. Glass, W. Hanke, R. Thomale, J. Schäfer and R. Claessen, Science, 2017, 357, 287.

11 S. S. Chou, Y.-K. Huang, J. Kim, B. Kaehr, B. M. Foley, P. Lu, C. Dykstra, P. E. Hopkins, C. J. Brinker, J. Huang and V. P. Dravid, J. Am. Chem. Soc., 2015, 137, 1742-1745.

12 Y. Guo, F. Pan, M. Ye, X. Sun, Y. Wang, J. Li, X. Zhang, H. Zhang, Y. Pan, Z. Song, J. Yang and J. Lu, ACS Appl. Mater. Interfaces, 2017, 9, 23128-23140.

13 X.-X. Li, Z.-Q. Fan, P.-Z. Liu, M.-L. Chen, X. Liu, C.-K. Jia, D.-M. Sun, X.-W. Jiang, Z. Han, V. Bouchiat, J.-J. Guo, J.-H. Chen and Z.-D. Zhang, Nat. Commun., 2017, 8, 970.
14 Z. Q. Shi, H. Li, Q. Q. Yuan, Y. H. Song, Y. Y. Lv, W. Shi, Z. Y. Jia, L. Gao, Y. B. Chen, W. Zhu and S. C. Li, Adv. Mater., 2018, 31, 1806130.

15 Z. Hui, Z. Jun, C. Ai-Qiang, Z. Lei, H. Zi and C. Ru-Shan, Nanotechnology, 2018, 29, 075201.

16 J. He, G. Ding, C. Zhong, S. Li, D. Li and G. Zhang, Nanoscale, 2019, 11, 356-364.

17 G.-Z. Wang, H. Chen, X.-K. Luo, H.-K. Yuan and A.-L. Kuang, Int. J. Quantum Chem., 2017, 117, e25424.

18 J. Zhang, T. Wang, D. Pohl, B. Rellinghaus, R. Dong, S. Liu, X. Zhuang and X. Feng, Angew. Chem., 2016, 55, 6702-6707.

19 P. Rivera, J. R. Schaibley, A. M. Jones, J. S. Ross, S. Wu, G. Aivazian, P. Klement, K. Seyler, G. Clark, N. J. Ghimire, J. Yan, D. G. Mandrus, W. Yao and X. Xu, Nat. Commun., 2015, 6, 6242.

20 K. S. Novoselov, A. Mishchenko, A. Carvalho and A. H. Castro Neto, Science, 2016, 353, aac9439.

21 Z.-Q. Fan, X.-W. Jiang, J. Chen and J.-W. Luo, ACS Appl. Mater. Interfaces, 2018, 10, 19271-19277.

22 Z.-Q. Fan, X.-W. Jiang, J.-W. Luo, L.-Y. Jiao, R. Huang, S.-S. Li and L.-W. Wang, Phys. Rev. B: Condens. Matter Mater. Phys., 2017, 96, 165402.

23 J. Heyd, G. E. Scuseria and M. Ernzerhof, J. Chem. Phys., 2003, 118, 8207-8215.

24 X. Zhao, M. Bo, Z. Huang, J. Zhou, C. Peng and L. Li, Appl. Surf. Sci., 2018, 462, 508-516.

25 S. Tan, Y. Dai, S. Zhang, L. Liu, J. Zhao and H. Petek, Phys. Rev. Lett., 2018, 120, 126801.

26 Y. R. Tang, Y. Zhang and J. X. Cao, J. Appl. Phys., 2016, 119, 195303. 